\title{
PLANEJAMENTO E CONTROLE FINANCEIRO: PESQUISA-AÇÃO EM UMA MICROEMPRESA VAREJISTA ${ }^{1}$
}

\author{
FINANCIAL PLANNING AND CONTROL: ACTION RESEARCH IN A \\ MICROENTERPRISE RETAILER
}

\author{
Ellen Cristina Baradel ${ }^{2}$ \\ Simone Martins ${ }^{3}$ \\ Adriel Rodrigues Oliveira ${ }^{4}$
}

\begin{abstract}
RESUMO: O presente estudo teve como objetivo principal identificar como são gerenciadas as entradas e saídas de caixa de uma microempresa comercial para a realização do planejamento e controle financeiro e demonstrar a importância da utilização de uma ferramenta gerencial para o processo decisório. Numa abordagem qualitativa, a pesquisa-ação é caracterizada como exploratória, descritiva, bibliográfica, documental e estudo de caso. Os dados secundários foram obtidos em documentos e os primários por meio de entrevistas semi-estruturadas e com a utilização do o programa Sphinx foi realizada análise de conteúdo. Os resultados comprovam que na microempresa analisada as decisões são centralizadas na pessoa do dono e que este não utiliza ferramenta gerencial para auxiliá-lo na tomada de decisão. Com a implementação do fluxo de caixa, verificou-se que a utilização de uma ferramenta gerencial possibilitou maior conhecimento do negócio, mas não foi suficiente para mudar a forma de gerenciamento utilizada.
\end{abstract}

PALAVRAS-CHAVE: planejamento financeiro, controle financeiro, fluxo de caixa

ABSTRACT: The present study had as main objective to identify how the inputs and outputs of cash flow of a commercial small business are managed for the accomplishment of the planning and financial control and to demonstrate the importance of the use of a managerial tool for the process of decision. In a qualitative approach, the research-action is characterized as exploratory, descriptive, bibliographical, documental and case study. The secondary data's were obtained in documents and the primary ones through semi-structured interviews and with the use of the the program Sphinx content analysis was accomplished. The results prove that in the analyzed small business the decisions are centralized in the owner's personnel and he doesn't use managerial tool in the process of decision. With the implementation of the cash flow, it have been verified that use of a managerial tool made possible larger knowledge of the business, but it was not enough to change the administration form used.

KEY WORDS: financial planning, financial control, cash flow

\footnotetext{
${ }^{1}$ Artigo Recebido em 27.07.2010. Revisado por pares em 03.11.2010. Recomendado em 28.04.2011 por Leomar dos Santos Editor. Publicado em 28.07.2011.

Organização Responsável pelo periódico: Universidade regional de Blumenau - FURB - www.furb.br/rn
}

\footnotetext{
${ }^{2}$ Universidade Federal de Tocantins - UFT - ellenbaradel@yahoo.com.br

${ }^{3}$ Universidade Federal de Tocantins - UFT - $\underline{\text { simone.m@ufv.br }}$

${ }^{4}$ Universidade Federal de Tocantins - UFT - $\underline{\text { aroli@ufv.br }}$
} 


\section{INTRODUÇÃO}

Na economia brasileira, as micro pequenas empresas são de suma importância, devido não só a geração de renda e emprego como também a sua capacidade em aumentar o nível de mercados formais. Banterli; Manolescu (s.d.) afirmam que elas somam 4,5 milhões de estabelecimentos, representando $30 \%$ do Produto Interno Bruto e $48 \%$ da produção nacional, sendo 22,3\% do ramo comercial e de serviço.

As micro e pequenas empresas podem ser assim classificadas através do número de funcionários, da receita bruta ou do faturamento anual e são, em sua maioria, do ramo comercial varejista. O ambiente interno das empresas em questão normalmente tem caráter familiar, apresentam um número pequeno de funcionários, em geral uma única pessoa realiza as funções de todas as diretorias e são classificadas como firma individual, pertencendo a uma única pessoa. Nessas empresas é comum observar problemas de obtenção de crédito e de gerenciamento financeiro, pois, dentre outros motivos, há dificuldade na separação do dinheiro próprio e da empresa, acumulação de tarefas, falta de conhecimento adequado por parte das pessoas e, ainda, pouca importância é dada para as questões gerenciais. Contudo, para sanar tamanhas dificuldades, o governo tem facilitado à obtenção de créditos e consequentemente a manutenção desse tipo de empresa na comunidade.

Perante essa realidade, acredita-se que o uso de ferramentas gerenciais possa minimizar os riscos causados pela escassez de recursos, uma vez que proporcionam aos gestores uma visão dos fatos que geram movimentação de recursos, e possibilita uma previsão e preparo dos acontecimentos futuros.

Diante do exposto, este estudo, enquanto uma pesquisa-ação imbuída da preocupação de dar suporte aos pequenos empresários tem como objetivo demonstrar a importância da utilização de uma ferramenta gerencial para o planejamento e controle financeiro de uma microempresa. A ferramenta selecionada foi o fluxo de caixa, cujo modelo foi desenvolvido considerando as peculiaridades da microempresa do seguimento comercial varejista, selecionada para o estudo. Trata-se de um modelo simples que permite analisar as entradas e saídas efetivas do dinheiro, possibilitando ao gestor uma visualização da situação financeira da empresa. Acredita-se que o estudo possa determinar o quão é necessário o uso de uma ferramenta gerencial para a realização do gerenciamento de caixa de uma microempresa.

\section{REFERENCIAL TEÓRICO}

\subsection{Microempresa}

As empresas podem se dividir em quatro ramos diferenciados: indústria, comércio, serviço e empresa mista, todas podendo ser de micro, pequeno, médio ou grande porte. Segundo Franco (1990), empresa é toda entidade jurídica que tem como objetivo principal obter lucros.

Neste trabalho o foco será numa microempresa varejista, sendo que esta é caracterizada por ser uma intermediária das empresas produtoras e dos consumidores, repassando o produto tal como o recebe, sem modificá-lo, não lhe agregando nenhum valor. (SEBRAE, 2008). Santângelo (s.d.) complementa dizendo que realiza atividade de varejo todo 
tipo de empreendimento comercial, que obtêm o faturamento através de vendas de pequenos lotes, independente de ser fabricante, distribuidor ou varejista.

O porte da empresa pode ser classificado com base em critérios quantitativos, qualitativos ou mistos, pois não há um padrão a ser seguido. Segundo Bernardi (2003) os critérios quantitativos são os mais utilizados pelo fato de apresentar uma facilidade em relação a sua coleta. Dentre os diversos critérios quantitativos, o faturamento e o número de empregados são os mais freqüentes indexadores, confirmado por Tavares (2004).

"Microempresa é um conceito criado pela Lei n. 7.256/84 e, atualmente, regulado pela Lei n. 9.841, de 5.10.99, que estabelece normas também para as empresas de pequeno porte, em atendimento ao disposto nos arts. 170 e 179 da Constituição Federal, favorecendo-as com tratamento diferenciado e simplificado nos campos administrativo, fiscal, previdenciário, trabalhista, creditício e de desenvolvimento empresarial.” (PALERMO, 2002, p. única).

A classificação como microempresa, definida em lei, veio para facilitar de maneira geral o seu desenvolvimento, ou seja, para possibilitar a sua entrada e permanência no mercado competitivo. Indriunas (s.d.) confirma que hoje a definição mais usual é a descrita na Lei Geral para as Micro e Pequenas Empresas, que define micro como sendo aquelas que apresentam um faturamento anual de até R $\$ 240$ mil, e pequena com inferior a R \$2,4 milhões de faturamento por ano. Este mesmo autor também apresenta o parâmetro dado pelo Sebrae (Serviço Brasileiro de Apoio ás Micro e Pequenas Empresas), que tem como critério o número de funcionários, sendo micro aquelas com até nove trabalhadores, no caso de comércio e serviços, e até 19 para o setor industrial e de construção; e pequena as que empregam entre 10 e 49 pessoas, no ramo de comércio e serviço, e de 20 a 99 no caso de indústrias e empresas de construção, que de acordo com Palermo (2002), também é o parâmetro utilizado pelo o IBGE . Outra definição apresentada por Indriunas (s.d.) é a utilizada por órgãos federais, como o BNDES, que caracteriza como microempresa as que apresentam receita bruta anual de até $\mathrm{R} \$ 1,2$ milhões e pequena empresa as que possuem receita bruta anual de no mínimo $\mathrm{R} \$ 1,2$ milhões e de no máximo $\mathrm{R} \$ 10,5$ milhões.

$\mathrm{Na}$ maioria das vezes, as micro e pequenas empresas, por serem firmas individuais, são gerenciadas por uma única pessoa, geralmente o próprio dono ou parente, o que pode acarretar diversos problemas, pois estes nem sempre têm o conhecimento adequado para realizar tal gerenciamento. (KASSAI, 1997). Uma empresa pode ser empregadora ou familiar. Segundo o SEBRAE (2008), as familiares têm características peculiares, tais como: postura de autoritarismo e austeridade por parte do fundador, com atitudes paternalísticas; vínculo de confiança acentuado em relação aos empregados; fortes laços efetivos; comando único e centralizado e estrutura administrativa simples. 


\subsection{Planejamento e Controle Financeiro}

O papel de um gestor financeiro é maximizar os recursos e para isso é necessário o uso de ferramentas que proporcionem informações precisas e rápidas, uma vez que planejar e controlar são medidas indispensáveis para a sobrevivência da empresa.

Através do planejamento financeiro é possível realizar uma gestão financeira eficiente, pois esta medida analisa antecipadamente os riscos, tornando mais fácil a solução de imprevistos. O planejamento financeiro é o responsável por determinar as diretrizes de uma empresa, como evidencia Ross (1995), ele se faz necessário por diversos motivos, tais como no estabelecimento de metas, decisão de investimento e financiamento a ser realizado, na minimização das surpresas e adequação às possíveis mudanças. O fato de realizar um planejamento faz com que as empresas estejam aptas a cumprir suas metas no futuro, de forma que controlar o planejado pode ocasionar alterações necessárias nas metas prédeterminadas diante de mudanças nas condições endógenas e/ou exógenas.

Os recursos da empresa podem ser mais bem utilizados se realizado um planejamento que contemple as necessidades da mesma. Segundo Gitman (2004), os planos financeiros e orçamentários são os principais fatores que ajudam a estabelecer um roteiro para atingir os objetivos da empresa, pois refletem em todos os setores, funcionando como mecanismo de controle para as demais atividades. Segundo Brasil (1999), o planejamento financeiro é de suma importância, mas também se deve ter a preocupação com o planejamento econômico.

Além disso, saber administrar o tempo significa poupar recursos, pois uma gestão bem desenvolvida nessa área pode proporcionar um ganho, de forma a diminuir um dos grandes problemas, a diferença de prazo entre os consumidores e os fornecedores. (BRASIL, 1999)

Para que a empresa possa cumprir com seus pagamentos nas datas corretas, é necessário que ela tenha um capital de giro suficiente, ou seja, a empresa precisa apresentar uma situação de liquidez. Esta situação, segundo Silva (2008), é resultado da junção dos fatores operacionais e estratégicos da empresa. Ter capital para cumprimento das obrigações significa ter controle sobre os itens circulante, em especial as contas do disponível, que possuem alta liquidez. (DI AUGUSTINI, 1996)

Brasil (1999) apresenta que algumas contas do Ativo Circulante não devem ser consideradas como disponíveis caso a empresa deseje continuar funcionando. A conta Estoque, por exemplo, ao vender a mercadoria, o valor deverá ser realocado para a manutenção dessa mesma conta, a fim de manter os produtos à venda. Esse tipo de conta só poderá ser considerado como realizável se a empresa decidir fechar. Desta forma, ter capital suficiente para suprir as necessidades básicas faz com que contas desse tipo não sofram com a falta de caixa da empresa.

Apresentar capital de giro pode ser um fator determinante para que sejam cumpridas as metas estabelecidas e para a sobrevivência da empresa no mercado. De acordo com Sousa (2007), capital de giro é o recurso financeiro existente na empresa capaz de suprir as necessidades do dia-a-dia. No mesmo sentido, Assaf Neto; Silva (1997) discorrem que capital de giro refere-se aos recursos de curto prazo que a empresa necessita para saudar suas dívidas, as quais são identificadas no Ativo e Passivo Circulante. Gitman (2004) se posiciona afirmando que capital de giro está relacionado com os ativos circulantes que sustentam as operações diárias da empresa. Este autor ainda destaca que um dos problemas de 
gerenciamento do capital de giro é devido aos prazos diferenciados para fornecedor e cliente, o que faz com que a empresa necessite de recursos para produzir antes mesmo de receber pela a venda.

A quantidade necessária para que a empresa mantenha um caixa suficiente para poder sanar suas obrigações à curto prazo, deve ser analisada de acordo com o ciclo operacional da mesma. Ciclo Operacional é o tempo que a empresa gasta desde a compra de seus materiais, para produção ou prestação de serviço, até o recebimento das vendas (SILVA, 2008). Uma análise errada pode fazer com que a empresa perca dinheiro, deixando de utilizar o capital em alguma atividade que proporcione melhor remuneração. É preciso analisar o custo de oportunidade de cada tomada de decisão para poder maximizar os resultados e analisar a rentabilidade do negócio. (DI AUGUSTINI, 1996)

A necessidade de capital de giro pode ser observada pela diferença do Ativo e Passivo Operacional (Di Augustini, 1996). Desta forma, a falta de capital de giro por muito tempo pode conduzir a empresa á insolvência, uma vez que a escassez de recurso pode fazer com que a empresa deixe de cumprir as obrigações.

Ao gerenciar uma empresa, o administrador deve-se atentar para a administração do capital de giro. Assim, conforme afirmado por Lima (s.d.) fatores como os ciclos econômicos e a sazonalidade específica do negócio devem ser altamente considerados para que o planejamento da empresa seja mais compatível com a realidade. Ainda segundo este autor, as empresas comerciais se atentam em obter um volume maior de capital de giro do que de ativos totais, concentrando-se nas contas a receber e estoques. Conforme foi colocado por Neves (2008) a sazonalidade sempre acontecerá, assim, cabe ao administrador saber geri-la de maneira favorável. Sazonalidade, segundo Pires (2008) é “à alternância de períodos previsíveis de baixas e altas de preços, em decorrência, respectivamente, de aumentos e diminuições na oferta de bens. Neves (2008) se posiciona afirmando que a sazonalidade não é algo desfavorável, pois se conciliada com ferramentas e estratégias, esta situação tende a ser favorável para a obtenção de melhores resultados para a empresa.

\subsection{Fluxo de Caixa}

Muitas vezes a empresa pode ter lucros sem fazer uso de métodos técnicos e sem realizar um planejamento, mas, segundo Sousa (2007), esta pode obter melhores resultados se for mais bem administrada, e se programar a gestão dos seus recursos. Uma administração sem planejamento faz com que o tomador de decisões seja subjetivo ao proferir suas escolhas, podendo muitas vezes desperdiçar melhores oportunidades. O referido autor ainda evidencia que o gerenciamento a ser utilizado pelas pequenas empresas não é muito diferente da utilizada nas grandes, é apenas mais simples, contudo, não se pode realizá-lo como antigamente, sem o mínimo de conhecimento financeiro.

A escassez de recursos financeiros e a falta de planejamento e controle fazem com que os gestores busquem informações precisas e oportunas para facilitar a tomada de decisão, por meio de ferramentas que demonstrem a realidade da empresa. O instrumento fluxo de caixa se atenta para a entrada e saída de dinheiro, considerando o princípio contábil do regime de caixa. Isto proporciona um maior auxílio no planejamento, pois permite conhecer o volume de 
capital necessário para realizar as atividades de curto prazo como também fazer uma melhor alocação dos recursos no longo prazo.

A ferramenta fluxo de caixa faz com que a gestão financeira seja mais eficaz, Zdanowicz (1998) afirma que o instrumento possibilita ao tomador de decisão realizar um planejamento, organizar, coordenar, dirigir e controlar os recursos financeiros durante um período de tempo. Por menor que seja a informação gerada pelo instrumento, é preferível ter alguma base no momento de tomada de decisão, pois seus riscos se tornam menores.

"o fluxo de caixa é processo pelo qual uma empresa gera e aplica seus recursos de caixa determinado pelas várias atividades desenvolvidas. (...) O fluxo de caixa focaliza a empresa como um todo, tratando das mais diversas entradas e saídas de caixa refletida por seus negócios”. Segundo Assaf Neto; Silva (1997, p.38).

Essa ferramenta dá suporte para que se acompanhem as entradas e saídas dos recursos financeiros, possibilitando o cumprimento dos objetivos e metas, tanto a curto como a longo prazo.

Sousa (2007) comenta que o uso da expressão fluxo de caixa refere-se a toda movimentação de recursos da empresa, independente da forma como este acontece, caixa, banco ou outras, mas que fluxo de caixa, como o próprio nome diz, se refere apenas a movimentação referente ao dinheiro em espécie ou representado como tal. Silva (2008) acrescenta que com a globalização, deve-se ter uma amplitude maior quanto à expressão fluxo de caixa, pois muitas operações são realizadas via internet, transferência bancária, cheques ou depósitos diretamente nos bancos, o que possibilita dizer que o fluxo de caixa vai além, envolvendo todos os pagamentos e recebimentos em geral.

Diante da ânsia de se obter sucesso, as informações geradas pela contabilidade clássica, ou seja, pelo Balanço Patrimonial, Demonstração de Resultado do Exercício e Demonstração de Origens e Aplicação dos Recursos, não são suficientes para controlar a liquidez da empresa, pois o lucro não é tudo. É preciso também haver compatibilidade de prazos, pois é fundamental que se tenha capital de giro. Assim, o fluxo de caixa permite a análise das movimentações, diferentemente das outras demonstrações que são estáticas, o que permite atualização permanente. Como é evidenciado tanto o passado como o futuro, é possível projetar o disponível para situação de escassez ou excesso de recurso.

O fluxo de caixa retrata a situação financeira da empresa, pois é realizado seguindo o principio contábil do regime de caixa. De acordo com Marion (2007) o regime de caixa considera como receitas e despesas do exercício aquelas efetivamente recebidas ou pagas dentro de um período, geralmente o ano comercial, e que apesar de não ser efetivamente legal, tem grande aderência por parte das empresas como contabilidade auxiliar. No caso das empresas sem fins lucrativos e das micro e pequenas empresas este regime é mais utilizado, uma vez que não se faz obrigatório o uso do Regime de Competência, que contabiliza as receitas e despesas do exercício social no ato do fato gerador, sendo independente a entrada ou saída de recursos financeiros. (MARION, 2007)

Segundo Silva (2008), a análise do fluxo de caixa pode ser feita em três etapas: operacional, estratégica e tática. A parte operacional permite formular conclusões a respeito do recebimento de clientes e do pagamento em geral. Na parte estratégica é possível obter 
informações acerca do comprometimento e liberação de recursos, aquisição de novas participações acionárias, volume de recursos de terceiros para longo prazo, montante de capital aportado pelos acionistas e quantia a ser paga aos dividendos. Já a parte tática é compreendida como sendo o volume de empréstimos à curto prazo, descontos de duplicatas, o montante desembolsado para pagar juros e as receitas financeiras do período.

É possível falar em dois tipos de fluxo de caixa, o realizado e o projetado. O realizado tem como finalidade mostrar as atividades operacionais, entrada e saída de recursos financeiros, durante o exercício financeiro da empresa. Ele dá base para o planejamento futuro, ou seja, torna possível a realização do fluxo de caixa projetado. É através deste que se analisa a sazonalidade da empresa, se existir. O fluxo de caixa projetado por sua vez, objetivase em antecipar as situações futuras que modificarão o caixa, possibilitando reajustar os recursos conforme a situação financeira, tanto no curto quanto no longo prazo. Ao se projetar à curto prazo o grau de certeza é muito mais elevado do que quando se projeta a longo prazo, devido à incerteza das informações. Porém por se tratar de projeção, independente do período projetado eles estão submetidos à subjetividade. A função do administrador é comparar o fluxo de caixa previsto e o realizado para analisar as variações e suas respectivas causas.

Este é um instrumento que pode ser utilizado por qualquer tipo e porte de empresa, a diferença está na forma de como será elaborado, pois este deve seguir as necessidades da mesma.

Neste contexto, a ferramenta fluxo de caixa visa melhorar a elaboração do planejamento e do controle financeiro, uma vez que a análise do capital de giro se torna mais fácil e as informações geradas refletem a situação econômica da empresa. Situação esta, importante para a tomada de decisão.

\section{PROCEDIMENTOS METODOLÓGICOS}

Este trabalho busca discutir a necessidade de utilização de uma ferramenta gerencial para o planejamento e controle financeiro de uma microempresa. Optou-se por realizar um estudo de caso único em microempresa do seguimento comercial varejista, bazar e papelaria, situada em Cabreúva, interior de São Paulo. A empresa foi escolhida por acessibilidade, levando em consideração disponibilidade para apresentar com clareza e sinceridade os dados necessários para a pesquisa.

O estudo de caso, segundo Gil (2007, p. 54), “consiste no estudo profundo e exaustivo de um ou poucos objetos, de maneira que permita seu amplo e detalhado conhecimento, tarefa praticamente impossível mediante outros delineamentos já considerados”. Yin (2002, p. 32) acrescenta que "um estudo de caso é uma investigação empírica que investiga um fenômeno contemporâneo dentro de seu contexto da vida real, especialmente quando os limites entre o fenômeno e o contexto não estão claramente definidos” e ainda explana que a capacidade de envolver diversas variedades é um fator diferenciador do estudo de caso. Vergara (2005, pg. 49) afirma "Estudo de caso é o circunscrito a uma ou pouca unidade, entendidas essas como pessoa, produto, empresa, órgão público, comunidade ou mesmo país”.

Considerando a necessidade de um envolvimento maior do pesquisador e dos demais sujeitos envolvidos sob o objeto investigado e, ainda, a necessidade atuação dos sujeitos em 
todos os processos de identificação de problemas, implementação de soluções e, posteriormente, avaliação, optou-se pela pesquisa-ação. A pesquisa-ação é "um tipo de pesquisa com base empírica que é concebida e realizada em estreita associação com uma ação ou com a resolução de um problema coletivo e no qual os pesquisadores e participantes representativos da situação ou do problema estão envolvidos de modo cooperativo ou participativo” (THIOLLENT apud GIL, 2007, p.55).

A pesquisa-ação teve início com reuniões e entrevistas que permitiram a elaboração de um diagnóstico e, em seguida, a formulação do problema e definição de estratégia para implementação de ações a serem desenvolvidas a partir de um trabalho conjunto dos pesquisadores e dos donos da microempresa.

A pesquisa também assume aspectos exploratórios pela escassez de informações sobre práticas de implementação de ferramenta gerencial para o controle e avaliação dos fluxos de caixa de microempresa. Gil (1995, p. 45) afirma que as pesquisas exploratórias têm como objetivo "proporcionar maior familiaridade com o problema, com vistas a torná-lo mais explícito ou a construir hipóteses”. O caráter descritivo também é apontado como uma característica do presente estudo, uma vez que busca fazer relação com o exposto na literatura e a realidade. Vergara (2005) explana que esse tipo de pesquisa diz respeito a determinada população ou fenômeno, sem o comprometimento de apresentar explicações dos acontecimentos descritos. Gil (2007) complementa afirmando que a pesquisa descritiva também pode estabelecer relação entre variáveis e que, na maioria das vezes, faz uso do questionário e da observação sistemática como técnica de coleta de dados. Segundo Cervo e Bervian (2002) as pesquisas descritivas tem como finalidade buscar uma relação entre as variáveis: freqüência do fato, a relação e conexão com outros episódios, a natureza e a característica do acontecimento.

$\mathrm{Na}$ coleta de dados, procurou-se obter evidências em diversas fontes de dados primários e secundários, o que permite classificar a pesquisa quanto aos procedimentos técnicos em documental e bibliográfica. De acordo com Gil (2007) pesquisa bibliográfica é desenvolvida através de materiais preparados, como livros e artigos científicos. Vergara (2005) acrescenta que este tipo de pesquisa fornece dados para qualquer outra, mas que também pode ser esgotado em si mesmo. Pesquisa documental, conforme descrito por Gil (2007) se assemelha muito a pesquisa bibliográfica, tendo como principal diferença a natureza das fontes, uma vez que é elaborada a partir de materiais que não recebem tratamento analítico. Cervo e Bervian (2002) afirmam que as pesquisas documentais têm o caráter de comprovar usos e costumes, tendências, diferenças e outras características. No caso deste trabalho, a pesquisa bibliográfica e documental servirá como base para o desenvolvimento de um estudo de caso, através da percepção de diversos autores sobre diversos assuntos.

Os dados primários foram coletados a partir de entrevistas semi-estruturadas, destinadas aos donos da empresa. As entrevistas foram realizadas em dois momentos, no ano 1, na fase do diagnóstico, e no ano 2, para avaliação da ferramenta "fluxo de caixa" implementada, conforme Ilustração 1, ao passo que os dados secundários foram obtidos através de pesquisa documental em manuscritos, relatórios, anotações, enfim, qualquer forma de registro mantida pela empresa. Esses dados foram utilizados para subsidiar a elaboração da ferramenta gerencial para controle dos fluxos de caixa. 


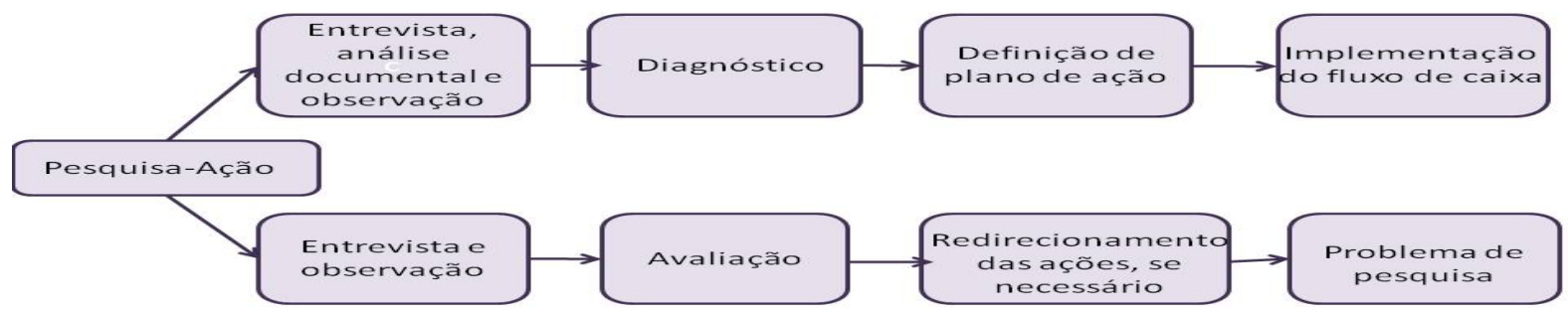

ILUSTRAÇÃO 1. Procedimentos adotados durante a pesquisa.

O trabalho objetivou demonstrar a importância de manter uma ferramenta gerencial para o controle financeiro, por meio da proposição de um modelo adaptado a microempresa. As informações foram estruturadas de modo a apresentar a trajetória metodológica do desenvolvimento e implementação do instrumento e da sua utilização pela organização. Para isso, a análise e apresentação dos resultados foram realizadas sob uma abordagem qualitativa, utilizando-se de análise descritiva.

Para análise dos dados foi utilizada a técnica análise de conteúdo, através de um minucioso exame das respostas dadas pelo administrador/proprietário, com base nos conceitos exibidos em literaturas. Segundo Vergara (2006, pg. 15) “a análise de conteúdo é considerada uma técnica para o tratamento de dados que visa identificar o que está sendo dito a respeito de determinado tema”. De acordo com este mesmo autora podem existir 3 tipos de categoria de análise: grade aberta, grade fechada e grade mista. Neste trabalho foi utilizada a categoria de grade fechada, na qual foi definida antecipadamente as categorias relacionadas com o objetivo da pesquisa, sendo elas: gerenciamento; planejamento e controle financeiro; recursos financeiros; e ferramenta gerencial.

\section{ANÁLISE DE RESULTADO}

A pesquisa teve como objetivo verificar a importância da utilização de uma ferramenta gerencial para o planejamento e controle financeiro de uma microempresa. Por meio de pesquisa-ação, os dados foram coletados durante 12 meses e as entrevistas realizadas em dois momentos. No mês 1, início da pesquisa, para elaboração do diagnóstico, momento em que foi verificado que a empresa não utiliza uma ferramenta gerencial. E, após a proposição e implementação do fluxo de caixa e utilização dessa ferramenta, pelos donos, para o planejamento da empresa.

A empresa analisada é uma microempresa varejista que comercializa produtos de papelaria, armarinho, brinquedo e presentes em geral. O quadro de funcionários é composto pelos donos (casal e dois filhos) e três empregados.

Deste modo apresentar-se-á os dados da visita inicial e os dados obtidos após a utilização da ferramenta.

\subsection{Análise do gerenciamento da empresa, visita inicial}

Com a primeira entrevista foi possível perceber que a empresa não possui nenhuma forma estruturada de gerenciamento financeiro. $\mathrm{Na}$ oportunidade, o gerente entrevistado relatou que o planejamento e controle financeiro eram realizados de maneira informal, o que 
não implicava em problemas para a empresa, devido ao porte e a pequena complexibilidade da mesma.

Para análise das entrevistas foi utilizada a grade fechada, sendo as categorias para o estudo: gerenciamento; planejamento e controle financeiro; recursos financeiros; e ferramenta gerencial.

\section{a) Gerenciamento}

Conforme discutido na revisão bibliográfica, pôde-se confirmar que na maioria das pequenas empresas, os proprietários são as únicas pessoas responsáveis pelo gerenciamento e que a estrutura familiar é marcante. Esse fato é comprovado na empresa analisada, na qual os donos (marido e esposa) são apresentados como sendo os responsáveis pelo controle geral da empresa (Ilustração 2). Os mesmos ainda evidenciam a preferência em contratar funcionários com algum grau de parentesco, devido à confiabilidade que esses transmitem em relação ao trabalho oferecido.

Embora por meio dos relatos tenha sido identificado que a gestão está a cargo dos donos, com a observação foi possível perceber que existe a centralização em uma única pessoa, o marido. Este, conforme a Ilustração 2 é o detentor do gerenciamento, sendo a mulher responsável por questões apenas operacionais. Apesar de não fazer uso de nenhuma ferramenta gerencial, o proprietário acredita que este fato não se traduz em prejuízo para a empresa, visto o reconhecimento da empresa perante a cidade, o que resulta no sucesso do empreendimento. $\mathrm{O}$ fator apontado como primordial para tal sucesso é a experiência com a atividade.

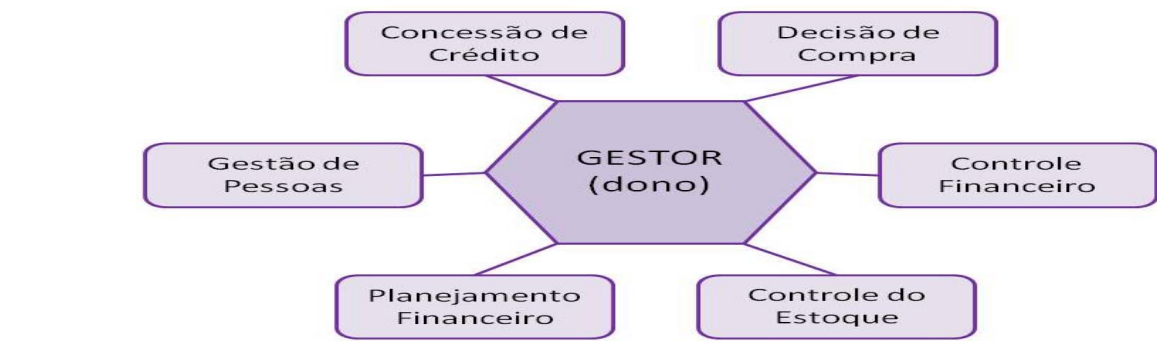

ILUSTRAÇÃO 2: Funções do gestor da empresa estudada.

No que tange ao controle de estoque, este é realizado a partir da visualização dos produtos nas prateleiras. O dono acredita que por fazer uso do estoque mínimo não existe a necessidade de utilizar um mecanismo para controlar as entradas e saídas de mercadoria, não contabilizando os produtos no momento da compra e nem no da venda. O proprietário evidencia que há um controle em relação ao fluxo de mercadoria, pois a menos que ocorra algum problema com um produto específico, a falta de um registro não compromete a disponibilidade dos bens para venda. Para o proprietário, ter sempre a mercadoria à disposição do "freguês" é tido como um fator importante para auferir clientes satisfeitos e obter bons resultados.

Ao decidir incluir ou excluir um produto, não é realizada nenhuma pesquisa de mercado. A decisão de excluir advém do proprietário, por este achar que o produto não é mais viável economicamente, que a procura esta pequena ou pela dificuldade de adquiri-lo. Já a decisão de incluir acontece, muitas vezes, pela procura dos clientes, pela influência dos 
fornecedores e também quando os donos vêem novos produtos e acreditam na potencialidade de venda em seu estabelecimento comercial. Desta forma pode-se inferir que a preocupação com os clientes não está em primeiro plano, uma vez que essas decisões buscam primeiramente se acordar com os princípios do proprietário.

No que tange a precificação na entrevista o dono se contradiz. Ele evidencia que o preço é colocado com base em indicações de fornecedores, em conversas informais, e pesquisa de mercado, através de visualização dos preços oferecidos por seus principais concorrentes. Porém, o mesmo aponta que os concorrentes não exercem influência em suas tomadas de decisões. O proprietário não tem remuneração fixa e também não tem o conhecimento da margem de lucro que aufere, só sabe a porcentagem acrescida sobre cada produto, que é diferente dependendo da procura e da concorrência que este tem na cidade. $\mathrm{O}$ valor a ser agregado ao produto é gerenciado pelo dono colocando-se preços mais baixos em produtos que chamam atenção, a fim de atrair novos clientes e estimular a entrada de pessoas em seu estabelecimento.

A sazonalidade é um fator presente no estabelecimento estudado, conforme apontado pelo gerente. Ele afirma que nas épocas sazonais existe uma tendência de diminuir os estoques e comprar produtos típicos da época, porém existe a preocupação para que não faltem produtos tidos como essenciais para o funcionamento do comércio. Para diminuir os riscos é realizado, na maioria das vezes, o pagamento das compras com dinheiro existente e em boas épocas, procura-se guardar dinheiro em caixa, a fim de suprir a falta de capital em temporadas menos favoráveis e se prevenir de algum acontecimento inesperado. O dono também utiliza como mecanismo para aumentar a entrada de dinheiro a oferta de promoções. Os principais produtos que sofrem com essa flexibilidade são evidenciados as áreas de papelaria e brinquedos, o que estimulou o dono a investir seu capital também em materiais de armarinho. Segundo ele "esses produtos apresentam uma procura, por parte dos clientes, durante todo o ano, o que ajuda a manter o fluxo de entrada de dinheiro em épocas que o setor de papelaria e de brinquedos estão em baixa”.

Para garantir as vendas durante todo o período o proprietário busca proporcionar aos clientes atratividades, como brindes e descontos especiais, oferecer bom atendimento e conquistá-los através de atendimento de encomendas especificas, mesmo que em alguns casos a mercadoria não seja um produto que a loja costuma comercializar. Ele acredita que tanto os agrados oferecidos aos clientes quanto a opção por colocar produtos atrativos com preços menores, ajudam a diminuir as diferença de entradas de dinheiro durante o ano.

O estabelecimento comercial varejista em questão adota como políticas de gerenciamento, não comprar a prazo, manter estoque baixo e fornecer produtos de boa qualidade com preço competitivo no mercado. Desta forma, como existe a preferência por realizar compras com pagamento a vista, a empresa busca receber de seus clientes no momento imediato da venda, preferencialmente em dinheiro. Entretanto, é de costume dos brasileiros realizar pagamentos à prazo e por esse motivo o estabelecimento adotou no ano passado a opção do cartão de crédito. Apesar de fazer uso também do recebimento em cheque, nos últimos anos, o gestor tem dificultado a compra com essa forma de pagamento, dando preferência ao uso de cartão, devido à despesa com inadimplência que os cheques geram à 
empresa. Para diminuir tais despesas, na compra com cheque faz-se necessário o cadastramento do cliente e normalmente o preço cobrado é mais alto.

O dinheiro auferido com as vendas das mercadorias é utilizado para realizar o pagamento das contas fixas, como escritório e vigilância; das despesas, com produtos de higiene, limpeza e outros; eventuais gastos; reposição de produtos e compra novas de mercadorias. O lucro, valor que sobra depois de descontado todas às saídas supracitadas, é utilizado para realização de benfeitorias na empresa e uso pessoal dos donos.

\section{b) Planejamento e Controle financeiro}

Ao considerar planejamento financeiro como sendo a determinação de diretrizes e estratégias, a fim de diminuir os imprevistos futuros, podemos dizer que até certo ponto o proprietário realiza um planejamento. Mesmo não o fazendo de maneira estruturada, o dono planeja semanalmente, através da visualização da falta de produto nas prateleiras e das contas a serem pagas, a quantidade a ser comprada e a destinação do dinheiro disponível. Entretanto por não utilizar capital de terceiros, não planeja a destinação do capital como forma de maximizá-lo.

Ao ser indagado a respeito de seu conhecimento sobre planejamento, o gerente respondeu que gerir o dinheiro disponível para a realização das compras e pagamentos das despesas é realizar planejamento. Porém planejar vai além do processo de decidir o que comprar e como saldar as dívidas.

Conforme explicitado pelo proprietário, ele não tem a preocupação de contabilizar seus custos para aplicar uma porcentagem sobre os produtos que tenham compatibilidade com os seus gastos. Ele sabe quais são as despesas normais, como: telefone, escritório, água, luz, e sabe que elas não variam muito, entretanto não tem o conhecimento de quanto isso compromete o seu lucro.

No que diz respeito ao controle financeiro este inexiste, se considerado que não há nenhum instrumento concreto para se realizar tal gerenciamento. Segundo o gestor não há um controle sobre todos os gastos, existindo apenas uma preocupação em não gastar mais do que o possui. As decisões são suportadas pela experiência, não fazendo o uso de qualquer conhecimento gerencial, da mesma forma que ocorre no planejamento.

O controle financeiro para o proprietário é importante apenas em relação ao valor excedente, o lucro. É apresentado que a principal preocupação gira em torno de manter sempre algum dinheiro em caixa para eventuais despesas não previsíveis. Da mesma maneira que acontece no planejamento, a decisão de comprar é tomada com base nas vendas realizadas e no controle visual de estoques, sendo este realizado semanalmente.

\section{c) Recursos Financeiros}

Os recursos que a empresa possui provem exclusivamente da venda de mercadorias, visto que a mesma não investe o capital em nenhuma outra atividade a não ser as que estão relacionadas com a atividade fim da empresa.

Para evitar captar recursos de terceiros, o empresário procura sempre manter uma quantidade de recursos disponíveis em caixa, contudo essa postura adotada faz com que os recursos não sejam maximizados, visto que dinheiro parado não gera receitas financeiras. $\mathrm{O}$ 
dono se preocupa pouco com o local em que este dinheiro vai ser guardado. Ele acredita que manter um dinheiro em caixa para eventuais despesas é mais importante do que tentar lucrar com as receitas que esse dinheiro poderia gerar, pois ele considera que a perda será maior se for preciso realizar algum financiamento a fim de suprir uma necessidade de capital.

A opção de não utilizar outro capital a não ser o próprio é justificada pelas altas taxas de juros. Já a explicação para o não investimento do capital excedente é a falta de conhecimento e a falta de tempo do proprietário para realizar tal função.

Os recursos financeiros são computados de maneira simples. O proprietário detém o gerenciamento e o controla sem nenhuma forma especifica. Ele evidencia que quando vai realizar as compras tem o conhecimento de quanto tem em caixa, não ultrapassa esse valor. Se necessário é utilizado o cheque pré-datado, controlado apenas através do contracheque.

\section{d) Ferramenta Gerencial}

O proprietário afirma que não faz uso de nenhuma ferramenta gerencial, mas que devido à sua experiência os controles e planejamentos ocorrem de maneira espontânea.

A forma como é gerenciado o estabelecimento vem permitindo resultados satisfatórios do ponto de vista do proprietário, com um fluxo de recursos considerado bom, uma vez que os produtos vêm obtendo uma movimentação de acordo com o esperado pelo dono.

\subsection{Análise do Gerenciamento, após implementação do fluxo de caixa}

Depois de evidenciado a inexistência de um instrumento para realização do gerenciamento financeiro da empresa foi proposta a utilização de uma ferramenta gerencial, o fluxo de caixa. O instrumento foi formulado de acordo com as necessidades da empresa e levando em consideração as limitações dos donos. A formulação da planilha foi realizada juntamente com o proprietário, a fim de criar uma familiaridade com o material a ser utilizado. Ao final de cada mês o proprietário fazia o repasse dos dados, procedimentos que se repetiu por um período de um ano. Ao final desse processo, uma nova entrevista foi realizada e agrupadas nas categorias anteriormente selecionadas, conforme informação a seguir.

\section{a) Gerenciamento}

Foi verificado que a ferramenta fluxo de caixa interferiu no planejamento e controle financeiro de maneira sutil, pois facilita a geração de informações precisas quanto à destinação dos recursos, porém não proporciona mudanças significativas no que tange as decisões de investimento.

O gestor, num primeiro momento, percebeu que o dinheiro é a forma mais utilizada pelos clientes para efetuarem os pagamentos, em detrimento do cartão e cheque. Tal fato pode ser comprovado pelo fluxo de caixa, em que foi demonstrado que o dinheiro corresponde à média percentual de 82,65\% das entradas de caixa, mesmo em momentos de maior consumo como o mês de fevereiro, justificado pela voltas-aulas. 


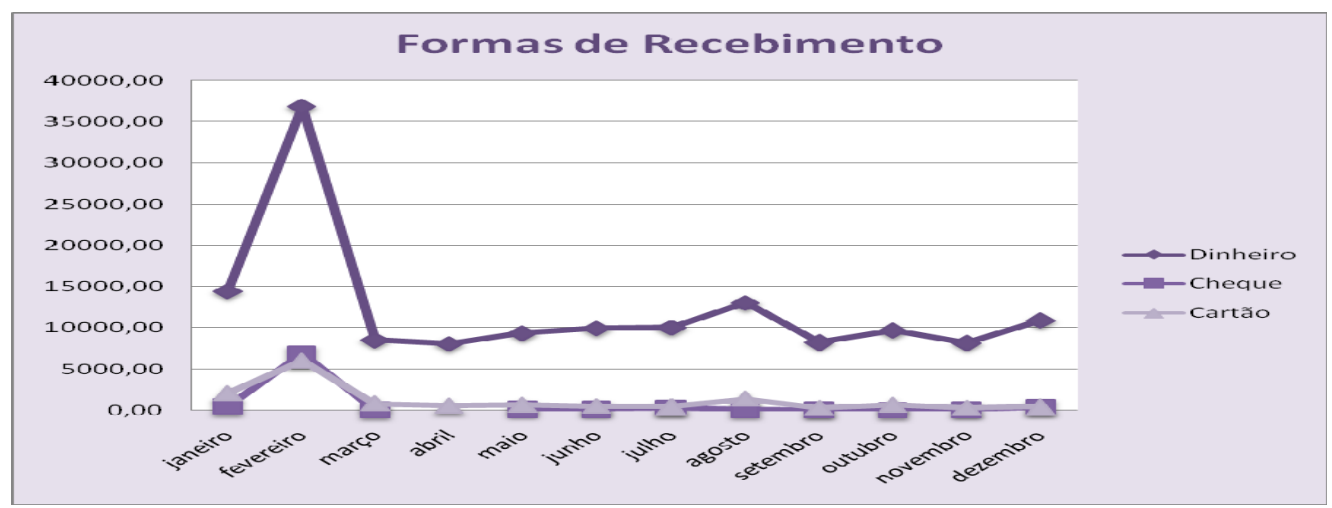

ILUSTRAÇÃO 3: Formas de Recebimento aceita pelo estabelecimento.

Com relação à política que vem sendo adotada pelo empresário a fim de diminuir a venda com cheque e incentivar o uso do cartão, com o fluxo de caixa foi possível observar que está obtendo resultados positivos, considerando uma pequena superação das vendas com cartão de crédito em relação às vendas com cheque, exceto para o mês de fevereiro.

Ao analisar o fluxo de caixa é possível perceber que a maior saída de dinheiro está relacionada com a compra de mercadorias e que o custo da empresa é muito baixo, o que posse ser visto como uma vantagem. O dispêndio de dinheiro com as despesas são, normalmente, referentes a contas como escritório, salário, telefone, água, luz, e serviços de terceiros (vigilância e limpeza da área externa), que são mais estáveis, o que facilita o gerenciamento da mesma.

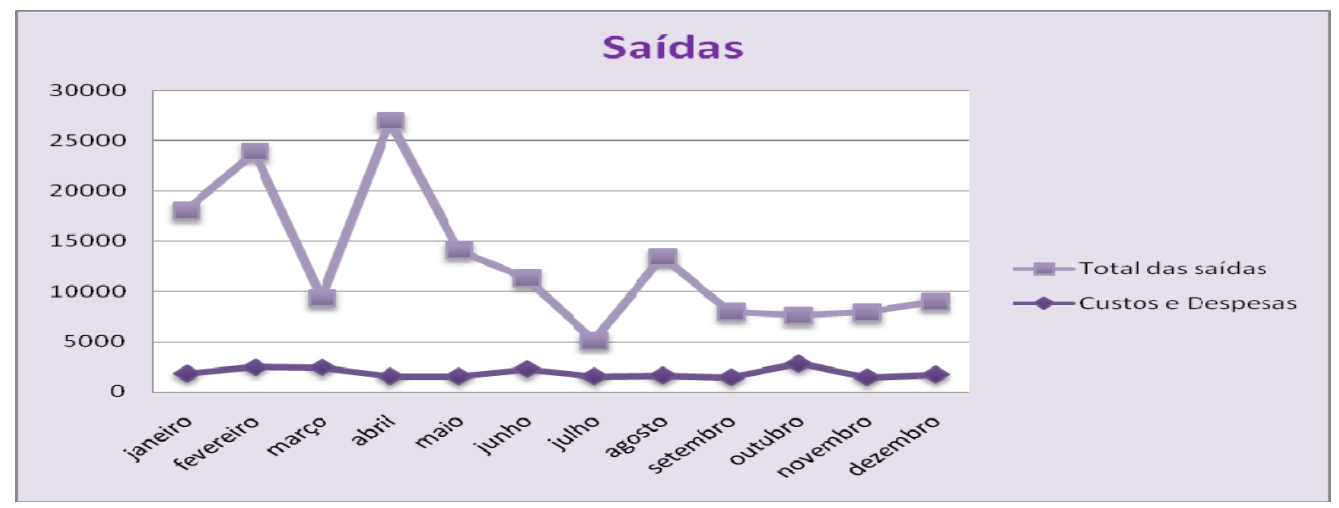

ILUSTRAÇÃO 4: Saída de caixa da empresa.

Antes de utilizar a ferramenta gerencial o proprietário manifestou a existência de épocas sazonais. Com a ferramenta, foi possível observar a discrepância das entradas e saídas com muita facilidade, como pode ser visualizado na Ilustração 5. 


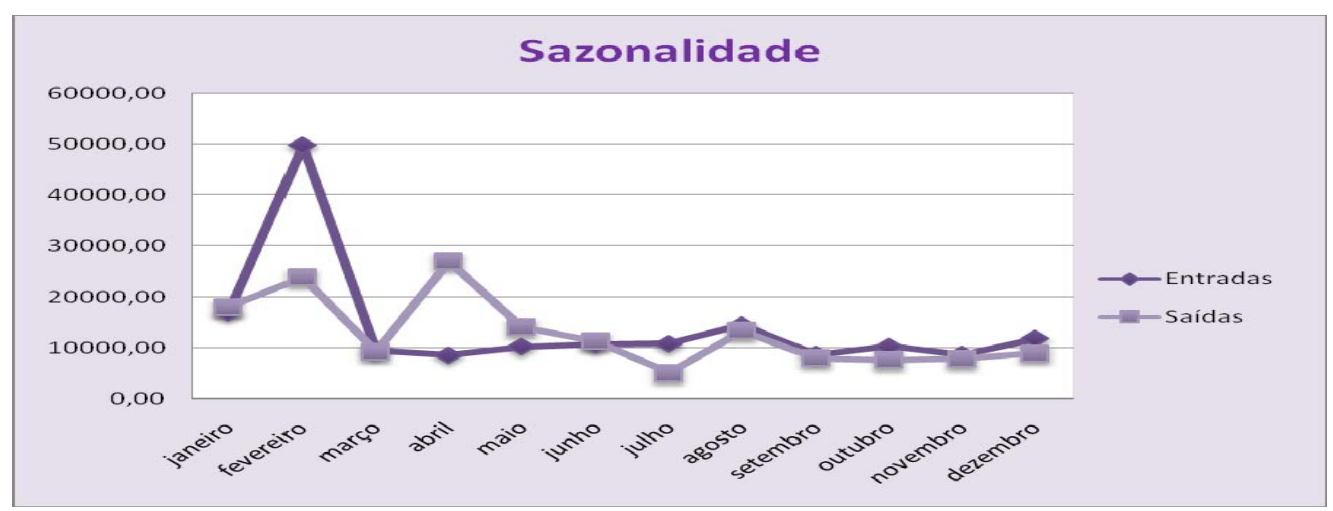

ILUSTRAÇÃO 5: Sazonalidade do fluxo de entradas e saídas. Fonte: dados pesquisa.

De acordo com a Ilustração 1 é possível perceber que as entradas, em alguns meses, não seguem a mesma variação que as saídas de recurso. Em abril é possível observar que as saídas representam um valor superior ao das entradas. Quando questionado sobre isso, o dono explicou que a ocorrência deste fato se deve aos prazos concedidos pelos fornecedores para a realização do pagamento de materiais escolares. Com exceção do mês de abril e maio, as saídas são condizentes com as entradas. Quando analisadas separadamente, é possível perceber que o período em que mais há entrada de recursos está relacionado com a época da volta às aulas, iniciando em janeiro e atingindo o ápice em fevereiro, fato que pode ser comprovado pelo aumento de 192,38\% (49769/17022) das entradas de fevereiro em relação ao mês anterior, e a queda de 81,05\% (9433/49769) de março em relação a fevereiro. No mês de agosto também é possivel observar um aumento das vendas em relação aos outros meses, o que também pode ser explicado por um voltas às aula, contudo em proporções bem menores. Os meses de outubro e dezembro, que são considerados pelo proprietário como meses sazonais, não podem ser evidenciados como tal no ano analisado.

No que tange a forma como é realizada a precificação, este obteve impactos positivos com a utilização da ferramenta gerencial. O gestor explicita que pode perceber facilmente que seus cálculos não são condizentes com os seus reais custos, entretanto ele afirma que ainda não tomou nenhuma atitude, optando por fazer a mudança à medida que ocorre a reposição de mercadorias.

\section{b) Planejamento e Controle Financeiro}

O planejamento e controle financeiro realizado pelo proprietário tiveram mudanças pouco significativas. O mesmo ainda continua realizando o planejamento de maneira informal, com base nas necessidades de compras de mercadorias e as despesas a serem pagas. Entretanto o dono evidencia que com a ferramenta e possível identificar a quantidade possível de gastos para o próximo mês, facilitando a tomada de decisão no que tangencia investimentos.

O fato do fluxo de caixa possibilitar uma melhor visualização do direcionamento do capital proporciona um maior controle sobre as despesas, principalmente as que não estão diretamente relacionadas com a atividade fim da empresa.

\section{c) Recursos Financeiros}


No que diz respeito à melhoria no rendimento da empresa não foi possível perceber nenhuma melhoria significativa, até porque para analisar o aumento ou queda dos resultados, é necessário analisar também questões exógenas, que no presente trabalho não foram consideradas. Porém, o dono afirma que o simples fato de prever com maior precisão a quantia que irá sair do caixa com despesas e gastos, permite uma melhora na gestão dos recursos.

No que tange ao investimento, o proprietário prefere manter uma postura mais conservadora, uma vez que não tem muito conhecimento sobre o assunto e o tempo lhe é escasso. O dono acredita que essa ferramenta não interfere no modo de investimento e financiamento, pois esta decisão depende da característica de quem gere o capital. Ele aponta que a ferramenta não mede os impactos que essa decisão pode gerar, ela só evidencia as entradas e saídas de caixa, ficando ao gestor a competência de decidir qual o melhor destino dos recursos. Também é exposto pelo responsável que fazer uso de financiamento não condiz com a realidade da empresa, visto que o capital próprio é suficiente para o funcionamento da atividade principal, não havendo a necessidade de mudar a política conservadora existente. $\mathrm{O}$ lucro ainda continua sendo destinado para melhorias na empresa e fins particulares dos proprietários.

\section{d) Ferramenta Gerencial}

Segundo o dono, a ferramenta possibilita a visualização da situação econômica ao final de mês, com dados monetários específicos da quantidade que foi vendida, comprada e outros gastos provenientes do mês, que antes não eram materializados, sendo muitas vezes esquecidos pela correria do dia-dia. Ele evidencia que poder saber o direcionamento dos gastos e despesas facilita a gestão de um recurso muito importante, o dinheiro.

Como ponto positivo de utilizar tal ferramenta, foi destacado pelo gestor, que esta conduz a um melhor controle dos gastos, que por sua vez faz com que os recursos sejam alocados de forma a aumentar a capacidade da empresa em gerar lucros. Criar o hábito de marcar as entradas e saída de dinheiro foi colocada pelo gerente como um fator limitante, mas que com o tempo se torna hábito. Porém ele evidencia que a utilização da ferramenta não causa nenhum impacto negativo, só tende a ajudar, com isso o fluxo de caixa pretende fazer parte do gerenciamento do proprietário.

\subsection{Antes e depois do Fluxo de Caixa}

No momento inicial, foi verificado que o proprietário não dispunha de nenhuma ferramenta gerencial, mas que devido à sua experiência os controles e planejamentos ocorrem de maneira espontânea, obtendo resultados satisfatórios do ponto de vista do proprietário, com um fluxo de recursos considerando bom, uma vez que os produtos vêm obtendo uma movimentação de acordo com o esperado pelo dono

Após a implementação do fluxo de caixa, segundo o dono, a ferramenta possibilitou a visualização da situação econômica ao final de mês, com dados monetários específicos da quantidade que foi vendida, comprada e outros gastos provenientes do mês, que antes não eram materializados, sendo muitas vezes esquecidos pela correria do dia-dia. Ele evidencia 
que poder saber o direcionamento dos gastos e despesas facilita a gestão de um recurso muito importante, o dinheiro.

Como ponto positivo de utilizar tal ferramenta, foi destacado pelo gestor, que esta conduz a um melhor controle dos gastos, que por sua vez faz com que os recursos sejam alocados de forma a aumentar a capacidade da empresa em gerar lucros. Criar o hábito de marcar as entradas e saída de dinheiro foi colocada pelo gerente como um fator limitante, mas que com o tempo se torna hábito. Porém ele evidencia que a utilização da ferramenta não causa nenhum impacto negativo, só tende a ajudar, com isso o fluxo de caixa pretende fazer parte do gerenciamento do proprietário.

\section{CONCLUSÃO}

Para atender os objetivos proposto neste estudo, esta pesquisa analisou a maneira como é gerenciado as entradas e saídas de caixa de uma microempresa comercial varejista, para a realização de um planejamento e controle financeiro. A empresa em questão não fazia uso de nenhum instrumento para realizar as funções gerenciais, com isso, foi implementada na mesma a ferramenta fluxo de caixa.

Mediante os resultados, pode-se inferir que a forma de gerenciamento do estabelecimento comercial não sofreu impactos diretos no planejamento e controle financeiro. A ferramenta possibilitou uma melhor visualização das entradas e saídas de caixa, com redimensionamento de alíquota de preço, análise das épocas que exigem maior saída de dinheiro, redução de custos desnecessários. Todavia a utilização de uma forma estruturada não alterou a maneira como o gerente faz o planejamento e controle financeiro, bem como não alterou a forma como e gerido o capital da empresa. As compras e vendas mantiveram-se sem contabilização e a forma de financiamento e investimento não modificou, preferindo conservar a postura adotada, com a utilização de capital próprio para financiamento e não utilizando o capital excedente para auferir receitas financeiras. No que se refere à separação do capital próprio e da empresa pode-se perceber que se manteve inalterado, desrespeitando o principio contábil da entidade, que explana sobre a importância da separação do dinheiro do sócio com o da empresa. Tal fato que pode ser explicado pela forma conservadora e paternalista como é gerido o dinheiro. A acumulação de tarefas, a falta de conhecimento adequado por parte do gerente e a pouca importância dada às questões gerenciais também foram observadas, comprovando as peculiaridades existentes em uma microempresa.

Como pontos positivos o fluxo de caixa facilitou a visualização das informações que antes não eram estruturadas. A tomada de decisão passou a ser embasada em dados que evidencia a realidade, possibilitando a tomada de decisões mais acertadas e minimizando decisões baseadas no "achismo" do dono. A precificação alterou-se, com base nas informações geradas pela ferramenta. Desta forma como essas modificações envolvem mudança de cultura, hábitos, espera-se que o fluxo de caixa ainda interfira positivamente na gestão da microempresa.

Este estudo serve de base para futuras pesquisas que estejam dispostas a investigar se o caso se aplica a outras empresas e identifica que fatores tais como precificação pode emergir novos trabalhos. 


\section{REFERENNCIAS}

ASSAF NETO, Alexandre; SILVA, César Augusto Tibúrcio. Administração de capital de giro. 2 ed. São Paulo: Atlas, 1997. 261 p.

BANTERLI, Fábio Rogério; MANOLESCU, Friedhilde Maria K. As Micro e pequenas empresas no Brasil e a sua importância para o desenvolvimento do País. Disponível em: <http://www.inicepg.univap.br/INIC_07/trabalhos/sociais/inic/INICG00512_010.pdf>. Acesso em: 23 set. 2008.

BERNARDI, Luiz Antonio. Manual de Empreendedorismo e Gestão. São Paulo: Atlas S.A., 2003. 320 p.

BRASIL, Haroldo Vinagre; BRASIL, Haroldo Guimarães. Gestão financeira das empresas: um modelo dinâmico. 4 ed. Rio de Janeiro: Qualitymark, 1999. 163 p.

CERVO, Amado Luiz; BERVIAN, Pedro Alcino. Metodologia Científica. 5ed. São Paulo: Pearson Prentice Hall, 2002. 242 p.

DI AUGUSTINI, Carlo Alberto. Capital de Giro: análise das alternativas, fonte de financiamento. São Paulo: Atlas, 1996. 272 p.

FRANCO, Hilário. Contabilidade comercial. 13 ed. São Paulo: Atlas, 1990. 296 p.

GIL, Antônio Carlos. Como Elaborar Projetos de Pesquisa. 4 ed. São Paulo: Atlas, 2007. 175 p.

GIL, Antonio C. Métodos e Técnicas de Pesquisa Social. São Paulo: Atlas, 1995. 207p.

GITMAN, Lawrence Jeffrey. Princípios de administração financeira. 10 ed. São Paulo: Addison Wesley, 2004. 776 p.

INDRIUNAS, Luis. Como funcionam as micros e pequenas empresas. Disponível em: $<$ http://empresasefinancas.hsw.uol.com.br/micro-e-pequenas-empresas-no-brasil1.htm>. Acesso em: 25 ago. 2008.

KASSAI, Silva. As empresas de pequeno porte e a contabilidade. Caderno de estudo. São Paulo: FIPECAFI, v.9, n¹5, Jan/Jun 1997. 60 -74 p.

MARION, José Carlos. Contabilidade Empresarial. 13 ed. São Paulo: Atlas, 2007. 501p.

NEVES, Ralph. A sazonalidade e a Administração. Disponível em:

$<$ http://ralphneves.wordpress.com/2008/05/12/a-sazonalidade-e-a-administracao/> Acesso em: 29 out. 2008.

PALERMO, Fernanda Kellner de Oliveira. As micro e pequenas empresas como propulsoras do desenvolvimento econômico e social. Contribuição para o incremento das atividades econômicas no âmbito do Mercosul.. Jus Navigandi, Teresina, ano 6, n. 55, mar. 2002. Disponível em: <http://jus2.uol.com.br/doutrina/texto.asp?id=2735>. Acesso em: 29 out. 2008 
PIRES, Valdemir. Sazonalidade. Disponível em:

<http://finpess.blogspot.com/2008/06/sazonalidade.html>. Acesso em: 09 jul. 2009.

ROSS, Stephen A; WESTERFIELD, Randolph W.; JAFFE, Jeffrey F. Tradução: Antonio Zoratto Sanvicente. Princípios de Administração Financeira. São Paulo: Atlas, 1995. 530 p.

SANTÂNGELO, Caio César Ferrari. O que é Varejo? Disponível em:

< HTTP://www.revistaportuaria.com.br/?home=artigos\&a=zom>. Acesso em: 16 set. 2008.

SEBRAE, Serviço Brasileiro de Apoio às Micro e Pequenas empresas. Principais características de uma empresa familiar. Disponível em:

$<$ http://www.sebrae.com.br/momento/quero-abrir-um-negocio/defina-negocio/tipos-denegocios/empresa-familiar/principais-caracteristicas-838/BIA_838/integra_bia>. Acesso em: 29 set. 2008.

SEBRAE, Serviço Brasileiro de Apoio às Micro e Pequenas empresas. Ramos de Atividade. Disponível em: <http://www.sebrae.com.br/momento/quero-abrir-um-negocio/definanegocio/ramos-de-atividade/sc_view?b_start_negocio:int=10\&-C=>. Acesso em: 23 set. 2008.

SILVA, José Pereira Da. Análise Financeira das empresas. 9 ed. São Paulo: Atlas, 2008. 522 p.

SOUSA, Antonio. Gerência Financeira para micro e pequenas empresas: um manual simplificado. Rio de Janeiro: Elsevier: SEBRAE, 2007. 150 p.

TAVARES, Bruno; A.T.F.C, Afonso; SILVEIRA, Suely de F.R. Pequenas empresas: definição, importância socioeconômica, taxa de mortalidade, características e outras considerações introdutórias. Viçosa: Universidade Federal de Viçosa. Nov. 2004 (Notas de Aula).

VERGARA, Sylvia Constant. Projetos e Relatórios de pesquisa em Administração. 6 ed. São Paulo: Atlas, 2005. 93 p.

VERGARA, Sylvia Constant. Métodos de pesquisa em administração. 2 ed. São Paulo: Atlas, 2006. 287 p.

VIEIRA, Marcelo M.F.; Zouain, Deborah Moraes. Pesquisa qualitativa em administração. 2 ed. Rio de Janeiro: FGV, 2006. 224 p.

YIN, Robert K. Estudo de Caso: planejamento e métodos. 2 ed. Porto Alegre: Bookman, 2002. 205 p.

ZDANOWICZ, José Eduardo. Fluxo de caixa: uma decisão de planejamento e controle financeiros. 7 ed. Porto Alegre: Sagra Luzzatto, 1998. 336 p. 